\title{
Article \\ System of Parametric Modelling and Assessing the Production Staff Utilisation as a Basis for Aggregate Production Planning
}

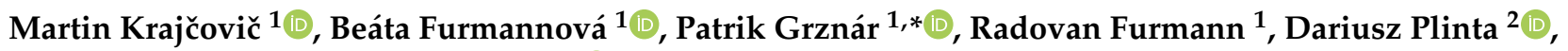 \\ Radovan Svitek ${ }^{1}$ and Ivan Antoniuk ${ }^{1}{ }^{1}$ \\ 1 Department of Industrial Engineering, Faculty of Mechanical Engineering, University of Žilina, \\ Univerzitná 8215/1, 01026 Žilina, Slovakia; martin.krajcovic@fstroj.uniza.sk (M.K.); \\ beata.furmannova@fstroj.uniza.sk (B.F.); radovan.furmann@fstroj.uniza.sk (R.F.); \\ radovan.svitek@fstroj.uniza.sk (R.S.); ivan.antoniuk@fstroj.uniza.sk (I.A.) \\ 2 Department of Production Engineering, Faculty of Mechanical Engineering and Computer Science, \\ University of Bielsko-Biala, ul. Willowa 2, 43-309 Bielsko-Biała, Poland; dplinta@ath.bielsko.pl \\ * Correspondence: patrik.grznar@fstroj.uniza.sk; Tel.: +421-41-513-2733
}

check for updates

Citation: Krajčovič, M.;

Furmannová, B.; Grznár, P.;

Furmann, R.; Plinta, D.; Svitek, R.;

Antoniuk, I. System of Parametric

Modelling and Assessing the

Production Staff Utilisation as a Basis

for Aggregate Production Planning.

Appl. Sci. 2021, 11, 9347. https://

doi.org/10.3390/app11199347

Academic Editor: Peter Trebuňa

Received: 20 September 2021

Accepted: 6 October 2021

Published: 8 October 2021

Publisher's Note: MDPI stays neutral with regard to jurisdictional claims in published maps and institutional affiliations.

Copyright: (c) 2021 by the authors. Licensee MDPI, Basel, Switzerland. This article is an open access article distributed under the terms and conditions of the Creative Commons Attribution (CC BY) license (https:/ / creativecommons.org/licenses/by/ $4.0 /)$.
Featured Application: The application in this article describes creating a data structure of the working activities in the framework of a parametric model for production operators. The project system calculates the working utilisation through the data structure and describes the methodology for assessing various variants.

Abstract: The requirement to achieve effective solutions in the shortest possible time in the manufacturing environment is essential, and it can be solved only by effective production planning methods. The scientific problem is that traditional methods for creating and assessing the production plans are insufficient for the future and it is necessary to look for new alternatives. The planners in the framework of designing the production layouts and subsequent capacity planning of the employees are missing the information, methods and tools for making clear decisions. The production costs in general and especially the costs for the workforce create a large part of the operating costs in many manufacturing enterprises. The scientific goal of the article is to present a design of the system for parametric modelling and assessing the working utilisation of the production staff intended for reducing costs. The described solution is based on object-oriented analysis and contains a methodology of planning and controlling the production process in the industrial environment. The designed methodology was used for developing a planning module of project software and was shown through a case study in a company dealing with the production of automotive components. Effective modelling of the digital copy of the manufacturing system in the software environment is one of the most difficult and important steps for developing reliable information systems for planning and inspection in the industry. The methodology's results in a company are that the solution can be used as a basis for the aggregate production planning that brings savings and efficiency increases. The research results can be used in any company with strictly defined working positions, working activities, and limiting conditions.

Keywords: modelling; manufacturing systems; optimisation of production planning; support of making decisions; advanced industrial engineering; digital engineering

\section{Introduction}

The majority of factories today face a lot of challenges in defining how to acquire and maintain their position in the competitive environment at home and abroad. The main challenge is to ensure the production, supply and customer processes are correctly implemented and stabilised. These processes transform the input material from one form into another one and increase its value [1,2]. The main goal of the factories today and also the enterprises in the future is to increase the value of the product effectively and to produce 
the smallest possible amounts of waste [3]. It is also necessary to increase the effectiveness from the point of view of the used time, the financial means, the necessary production space and operation of the production staff [4]. For the constant increase in productivity and long-term sustainability of the factory, these processes and operations have to be designed and arranged in such a way they will enable a continuous and controlled material flow through the plant $[5,6]$.

According to [7], the main goal of the production layout redesign is to design an effective technological flow emphasising the increase in the machinery productivity, the shortening of the material flow and employees' operation as well as a design of the longterm sustainable manufacturing systems. The pressure on constant cost reduction is in the area of interest of almost all manufacturing companies. The price reflects the competitiveness and sustainability of the company. A lot of the company costs are connected with production efficiency. The more effectively the materials are transformed into the products in the required quality, the higher productivity of the factories is achieved and, as a result, the working level of the employees' utilisation will also improve [8,9]. In the framework of designing the production layouts and subsequent production planning, engineers often encounter complicated and sometimes contradictory requirements and a lot of limiting conditions. All of this stimulates the effort to form new and progressive approaches to creating and assessing the production layouts [10].

The management-in the case of designing the production layouts and subsequent capacity planning of the production workers-is missing data, information, methods and tools for an unambiguous assessment. Therefore, the development of the software solutions in the area of the capacity planning of the production employees and software for the production design has been largely emphasised recently [11]. The problem consists in the fact that the current planning procedures are based on principles that have been used for more than a century. The majority of the data in the companies are in the electronic form (approximately 60\%); however, the problem is that they do not create any structural units that could be used for the capacity dimensioning and assessing the utilisation of the manufacturing employees [12]. Some data (approximately 40\%) are collected and assessed in one-day intervals and saved in the hard copy form, and are operatively utilised for identifying the problems with production saved in the company archives. Their usage is very laborious and time-consuming. The current companies are also missing a unified software solution for the capacity dimensioning of the employees that would be based on the data from the manufacturing processes, bound with particular activities of the manufacturing procedure (a digital data model of production is missing). The research has always responded to the needs of society and these needs have been transformed into scientific knowledge [13-15]. The purpose of the innovative approaches in the production planning area is to provide the users with better and more sophisticated designs in the shortest possible time. The designs have to include individual limiting conditions and company priorities [16]. For the new technologies to be implemented, the companies have to be able to combine the utilisation of the latest and available technologies [17]. For their utilisation, it is inevitable for the companies to be aware of the current development trends and values added to the new innovative solutions.

A few scientific works have dealt with aggregate production planning [18,19]. They bring case studies dealing with the linear models of the cooperative aggregate planning $[20,21]$ by the MDM methodology (Multiple-Domain Matrix) for acquiring knowledge and designs for improvement [22], the object-oriented analyses implemented to the industrial software $[23,24]$, the aggregate stochastic network model for optimal management of the production planning [25]. The studies describe the aggregate planning and the area of the staff capacity planning in different ways; however, this is without any complex analysis of the elementary tasks necessary for maintaining the stable production of a certain product and feedback during changing the production parameters.

There are currently methodologies for both aggregated planning and utilisation of positions, but there is a lack of a certain methodology and functional tool that would allow 
flexibly to address the redesign of workplaces and equipment to ensure the production of workplaces through activities. For example, [26] develops a model for allocating crosstrained workers at the beginning of a shift in a multidepartment service environment, [27] and [28] solved utilisation of workers in sorting warehouse by genetic algorithm and by classical steps of simulation experiment and [29] solves the problem of worker utilisation in healthcare. The proposed methodology and tool differ because they show how to combine design from areas of capacity workload with a focus on human resources that allows for the quick testing of the utilisation variant by model parametrization.

We chose the software solution CEIT Table in the framework of which we created the architecture of the planning module that ensures the data integrity (the defined working activities for ensuring production) and the assessment of the necessary capacities of the production staff for implementing our solution, the methodology for dimensioning the capacity of the production employees. As the basic part of the software solution has been included in previous research at the Department of Industrial Engineering at the University of Žilina, we connected the module of designing the production layout with the architecture of the planning module. In this way, we are able to acquire information and feedback between the designed production layout and capacity utilisation of the staff (placement of the measuring devices and other auxiliary objects, the influence of the multi-layer operation, the frequency of the transfers between operations).

\section{Materials and Methods}

In this work, we aim at the aggregate planning area with regard to capacity dimensioning of the production staff and the creation of the digital data model of production for the long-term sustainability of the planned production.

\subsection{Aggregate Planning of the Production Staff}

The basic goal in the majority of manufacturing enterprises is to satisfy the demand for products through effective utilisation of their resources, e.g., the production equipment and workforce. The aggregate planning serves for supporting the development of the optimal production planning, for fulfilling the forecast demand in the future in a medium-term horizon. This planning procedure aggregates the demand for the capacity in the given time and states solutions for the required capacity. The objective is to find a possible solution through the internal possibilities of the company that have to correspond with the requirements on the production volume or to find the optimum by defining the solution that minimises the costs and fulfils the capacity requirements.

The steps for creating an aggregate plan begin by determining the demand and defining the current production capacity. The capacity is expressed as a volume of production units that can be produced per a certain time period (this requires determining the approximate number as the manufacturing process can consist of several products that require different production times and costs). The demand is expressed as the total number of units that are to be delivered. If these two aspects are not in balance (they do not equal), the company has to decide if to increase or reduce the production capacity to fulfil the demand or to increase or decrease the demand to fulfil the production capacity.

There are several situations when the company needs to increase or reduce the production requirements (reducing the price or making it more advantageous, the possibility to pre-order the products, etc.). However, this solution deals with the area of the capacity planning of the manufacturing staff and thus with the possibilities of increasing or reducing their production capacity to achieve the level of the current demand. Here we can mention [30]:

- Overtime - the company can temporarily increase the production capacity without increasing the costs or hiring employees through ordering or asking them to work a certain amount of hours daily or days weekly. 
- $\quad$ Training for several working positions - the employees trained for several working positions are able to carry out several operations at the same time and this fact brings a certain flexibility of the production capacity planning.

- Part-time employees-the utilisation of the part-time employees or casual workers (the employees who are considered permanent employees, however, they are used only when they are necessary and usually without the benefits of the workers with permanent jobs) can change the production capacity and solve the fluctuation of the demand [31].

- Hiring employees/unpaid leave-the balance between the production capacity and demand can be maintained through hiring additional workers when it is necessary and unpaid leave when the employees are not currently utilised for fulfilling the company's demand.

1. The current manufacturing enterprises utilise two basic strategies for their aggregate plans-the synchronisation and emancipation strategies. They can be used individually or in a combination.

2. The synchronisation strategy-utilises covering the production capacity and demand from period to period. This causes frequent hiring processes, making redundant or unpaid leaves, dissatisfied and uncertain employees, increased costs for storing residual inventories, problems with the Trade Unions and unstable utilisation of the manufacturing equipment. On the other hand, it means high flexibility of the company. The main advantage of the synchronisation strategy is that it allows keeping minimal inventories and it means big savings for some companies. The majority of the enterprises working on the "just-in-time" basis use the synchronisation strategy also for the aggregate planning.

The emancipation strategy_creates an aggregate plan bringing a stable level of production and employment. To fulfil the changes in the demand for the product the company has to increase or reduce the inventory volume of the finished goods in compliance with the forecasts of changes in the demand. The company maintains the size of the workforce as well as the production also during the period when the demand is low. This fact gives the company an opportunity to create larger inventories than they are necessary at that moment. When the demand is increased, the company is able to maintain the volume of the workforce/production because the created surplus will cover the increased demand for the product. The strategy of balance allows the company to keep an excessive production volume and at the same time to fulfil the requirements of the demand. This is an acceptable form for companies with a positive relation to the employees. The negative impacts of the balancing strategy are mainly the higher costs for storing the excessive inventories, the costs for overtimes or delivery services.

The strategy utilising the time-cascading principle-the majority of the companies consider it advantageous to utilise a combination of both previous strategies. The combination will bring a situation when the capacities will be changed in leaps with a longer time interval and will remain constant in the given time interval. It can be a better strategy for fulfilling the organisational objectives and regulations and it will result in lower costs than when we make use of the individual strategies separately.

\subsection{Mathematical Approach to Aggregate Planning}

The following mathematical techniques are the best known and can be used for a more complex solution of the aggregate planning area:

Linear programming -is an optimisation technique that offers to find the maximal profit, receipts or minimal costs on the basis of limited resources. The special type of linear programming known as the transport model can be used for creating an aggregate plan that will help balance the production capacity and demand at minimal costs. However, only a few decisions of aggregate planning are compatible with the assumptions of linear programming [32]. 
Mixed integer linear programming (MILP) — the MILP can be very useful for those aggregate plans that are prepared for a whole wide range of products where the plan is a summarisation of the plans for individual product lines. This approach offers a method for determining the number of units that are to be manufactured for each group of products [33].

Linear decision rule (LDR)—an optimisation technique that looks for minimising the production costs (work, overtime, hiring/unpaid leave, storage costs for overproduction) utilises a range of functions for an approximate cost estimation (three of them are quadratic) to achieve a single quadratic equation. After that (using the calculation) two linear equations can be derived from the quadratic equation, one of them for planning production for each time period and the second one for planning the workforce for each time period [33].

Management coefficients model—formulated by [34] is based on an assumption that the size of production is adjusted by this general decision-making rule:

$$
P_{t}=a * W_{t-1}-b * I_{t-1}+c * F_{t+1}+K
$$

where $P_{t}$ is the production amount per $t, W_{t-1}$ is the workforce for the previous time period, $I_{t-1}$ are the inventories at the end of the previous time-period, $F_{t+1}$ is the demand forecast for the next time-period, $a, b, c, K$ are the constants.

Then the regression analysis for estimating the values $a, b, c$, and $K$ is used. The final result is the decision-making rule based on the previous management behaviour without any further functions of the explicit costs. There is an assumption that the managers know what is important although it is not easy to identify these costs. This method completes the usage of the experience assessment [33].

Search decision rule (SDR) - is a methodology that does not have several limitations of the linear assumption of the costs in the linear programming framework. The SDR allows the user to determine the values of the costs only on a very general level. That requires the computer programme to be created in such a way it will assess the costs for each plan. Then we look for that plan among all available ones which has the lowest production costs. Compared with linear programming there is no certainty of finding any optimum [35].

Simulation-we can use a lot of simulation models for aggregate planning. The development of the aggregate plan (in the simulation model environment) can be tested under a lot of conditions to find a satisfactory plan. These models can be also included in the decision support system that can help plan and analyse the alternative check rules. These models can have several integrated conflict objectives in the manufacturing strategy by using various quantitative measurements of productivity, customer services and flexibility [36].

Approach of functional objective search (FOS) - is a computer aggregate planning system that contains a wide spectrum of real planning conditions. It can create realistic, low-cost operating plans that provide possibilities to achieve different planning objectives. The systems work on the basis of comparing the basic planned load and the available capacity. When the manager selects the required activities and connected planning goals for the particular conditions of load, the system considers each planning objective in such a way it will reflect the functional emphasis that is behind its achievement under certain conditions of load. The computer then creates a plan through the search function that will minimise the costs and fulfil the delivery terms [36].

\subsection{Virtual Data Production Model in the Digital Twin Concept}

The company has to possess correct data about the development of the production. The manufacturing environment is often fragmented and heterogeneous working as groups of independent production islands. Although the production islands can work highly effectively, the whole manufacturing system can seem like an untuned orchestra. In this environment we use only the local optimisations; any global optimisation of the whole manufacturing system is missing. Modern companies have to ensure a transparent course of production and strict registration of all events inside of it. The life of each product in the 
production system has to be exactly recorded in such a way that we will be able to follow it, if necessary, also in the future. These functions are nowadays ensured by the modern systems of production management [37].

The digital company is built on the basis of the scheme in Figure 1 where people, manufacturing machines, equipment, products and logistic systems are able to communicate and collaborate with each other [38]. The reason for connecting the digital and virtual world of the enterprise is the utilisation of a huge amount of data for making faster and more appropriate decisions. The interconnection of the products, manufacturing devices and people increases the effectiveness of the manufacturing machines and equipment; it saves resources and reduces the costs.

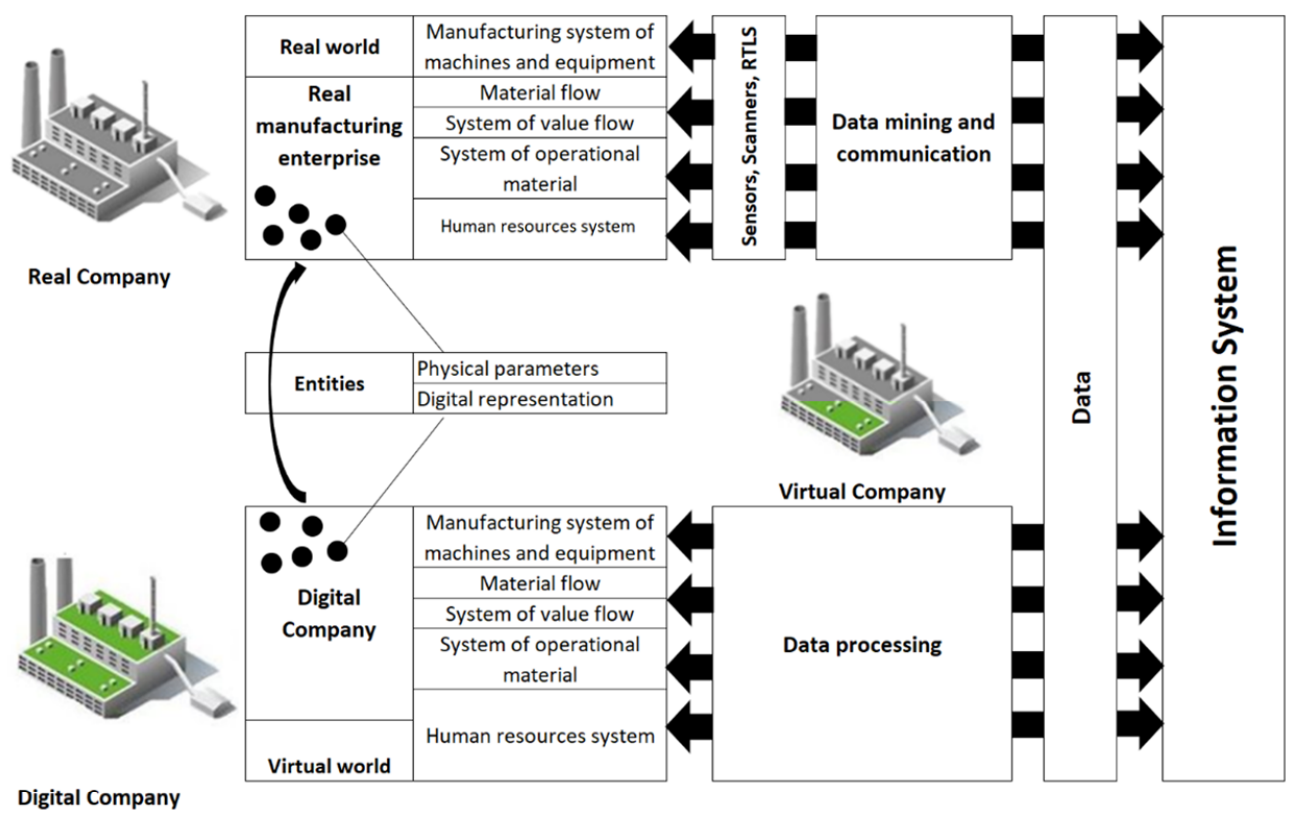

Figure 1. Factory digital twin. (source: Authors).

The virtual company (the production data model) contains a lot of data that can be analysed and in the case of its collection and updating in real-time used for prediction. This would create a dynamic picture of the real production [39]. Through connecting all these three parts-the real, virtual and digital ones into one environment the so-called factory digital twin develops.

When we are developing reliable software systems for supporting the planning and control procedures in the industry, the most difficult and most important step is to create an effective method of modelling a digital and data copy of the manufacturing system. Based on several studies $[39,40]$ verified design methodologies of the manufacturing systems in the digital company environment consist of the following stages:

1. The introductory stage-acquiring the basic knowledge about the manufacturing assortment for which the production layout is being designed.

2. The project structure-this stage describes two basic activities-the definition of the manufacturing product and the current state analysis.

3. The process planning - the main part is created by processing the knowledge about the manufacturing processes.

4. The resource structure-creating the flow diagram dealing with complex analysis and realisation of the structure of the manufacturing system resources.

5. The realisation of the manufacturing layout—creating a digital model on the basis of findings from the previous stages.

In cooperation with the IE department, we were able to identify the basic working instructions affecting the nature of the manufacturing employees' operation. For us to be 
able to set up their parametric digital model of utilisation regarding individual activities, our project team had to define the following analysis areas:

- The technological procedures, job designs of the manufacturing plan, cycle times of the machines.

- The trial procedures and lists of the measurement devices for production.

- The setup plans and instruction relating to the life span of individual tools.

- The working instructions and working procedures for the machine operators.

- The competencies of the operators, the dot plan.

- The matrix of the machine set up with requirements on time.

- The autonomous maintenance plan at the workplaces.

The basic problems connected with the input data for setting up a parametric model of the production employees' utilisation are as follows:

- Inaccurate planning due to inexact or incomplete data.

- The missing or inhomogeneous software and rules, shortages in the information flow.

- The human errors resulting from an inappropriate working system, missing rules.

- The overdimensioned/underdimensioned capacities (employees, handling technique, surfaces).

- The difficult acquisition of the data, the insufficient validity and timeliness of the information.

- The undefined valid regulations or only partial ones, missing rules, an insufficient overview about the information flow across the supporting departments.

\subsection{Interactive Design System}

Design and control of the modern manufacturing system with more than one monitored indicator, and for which complex parametric models are used, need to have interconnection between utilised methods and computer technique. The computer hardware has to include suitable software for creating and analysing the designed solutions.

During previous research [41], we created the basic part of the software module CEIT Table (see Figure 2) that serves for designing production and forming a three-dimensional model of the production stage. It is an interactive tool for effective team planning of the production and logistic systems. It enables designing a logical or production concept through the 3D models and selecting the best variant thanks to the analyses.

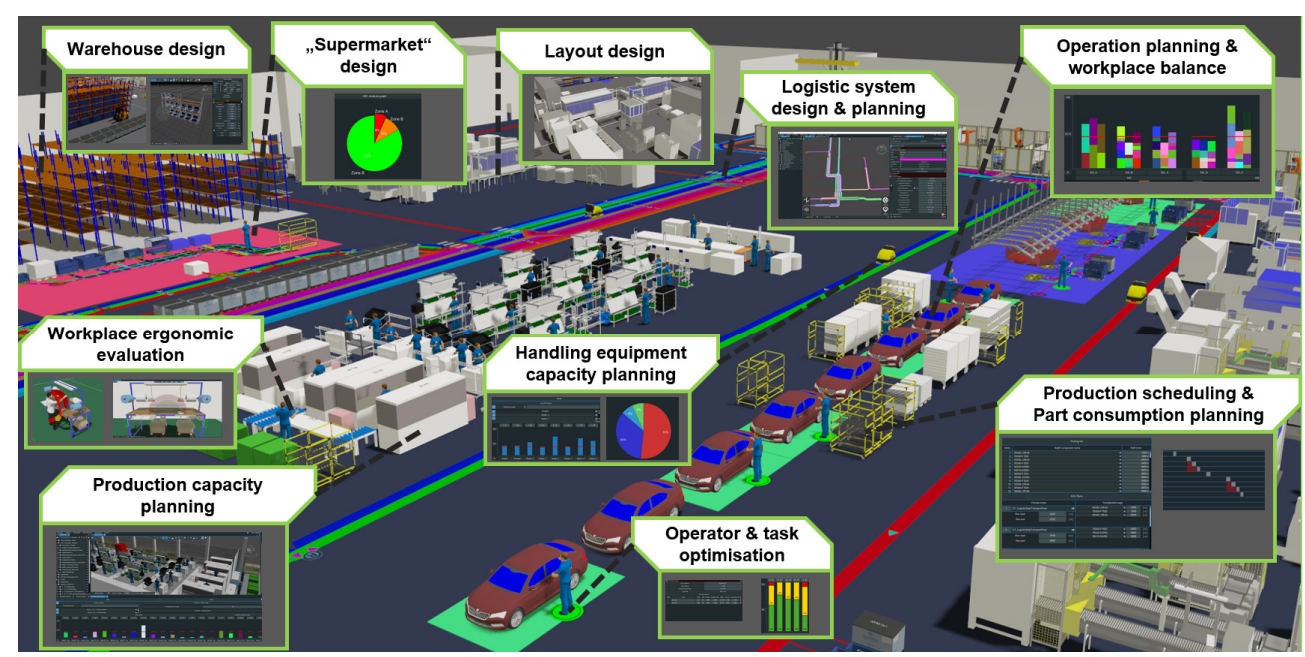

Figure 2. Development of the interactive design system CEIT Table. (source: Authors).

It represents an innovative approach to planning and designing the production and logistic systems. During the workshops, the project team members can change the production layout through the touch screen and thanks to the software's interactive character to recognise the effects of the realised changes because the system is able to re-draw the material flows and to calculate the followed indicators. It gives answers to the questions- "What will happen, if?". 
The advantage of the software environment is the creation of complex models of the manufacturing, logistic and warehousing system. The space layout is created by the parametric models that are typical besides their three-dimensional space interpretation also by an adjusted selection of behaviours and properties (the physical properties, various production parameters, etc.) based on which the system assesses the indicators observed.

The disadvantage is that the design system has no complex system for assessing the employees that would take into account all areas we defined as well as their mutual interconnection. This disadvantage means for us a space for investigating the possibilities to implement the authors' methodology for parametric modelling and assessing the working utilisation of the manufacturing staff serving as a basis for the aggregate production planning.

\section{Results}

\subsection{Implementation of Parametric Modelling of Manufacturing Staff's Utilisation}

Before specifying the requirements for how to solve the problem, it is necessary to determine where the application will be used. First of all, it is necessary to state for which type of manufacturing systems the solution will be determined because the differences between the production systems can be large-e.g., the production volume, the utilised technologies, the handling methods or other aspects. For implementing our solution we defined the classical small to medium-sized engineering series production and assumed handling with the piece material. For determining the most suitable parameters as well as the overall form of the solution's representation it is necessary to define the requirements that this solution is to fulfil at first. After specifying the usage of the application the requirements on the solution are as follows:

1. We determined the possibility of interconnecting the solution with the planned software for creating the 3D layouts as one of the key requirements.

2. The possibility to specify the layout solution maintaining the variedness of the created manufacturing systems and possible demands that are placed on them. In the framework of the created parametric model, it is important to implement the possibility of adjusting the parameters or a closer specification of the searched solution to acquire results of a higher quality.

3. The utilisation of the parametric data production model, the core of the solution will utilise the database of the determined activities (components) of the manufacturing staff. The activities have time requirements specified by the MTM UAS methodology.

4. The record and visualisation of the outputs-in the framework of setting up the model - are to be handed over to the user briefly and clearly. After completion, it is also necessary to visualise the achieved solution in a suitable way.

5. The transparency and simplicity of the user interface, entering the input data and specification of the required solution should be listed in a transparent way according to individual sections and has to be simple for usage.

The software architecture contains five basic blocks (see Figure 3) that are mutually interconnected. The first block is the design software module that will model the digital production model. The module for the planning support includes the imported input data and transfers the results into the statistical module where the results are collected in an understandable way for depicting in diagrams and subsequent exporting through the procedure of the designed methodology. The software library serves for saving the individual models and components of the system for usage in the future and the interactive design system itself comprises the functions of all surrounding modules and offers a graphical interface or simple control and usage. 


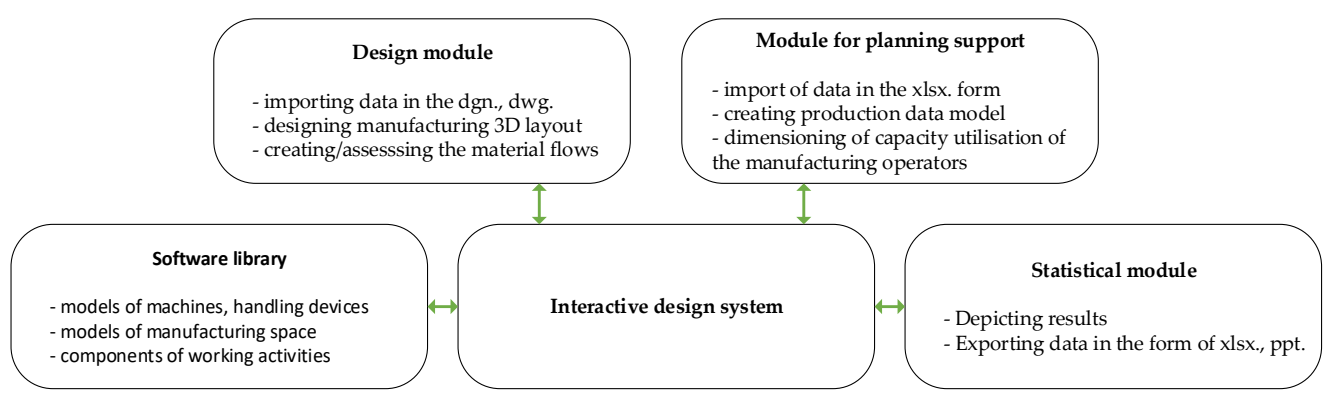

Figure 3. Designed interconnection of individual modules of the design system. (source: Authors).

\subsection{Creating the Digital Model of Production Layout}

After taking into account the individual modules, previous steps and the necessary outputs for the subsequent aggregate production planning we created a methodology of dimensioning the utilisation of the production staff using the parametric data model of production (see Figure 4). In the next stages we will specify and describe the steps of the methodology itself as follows:

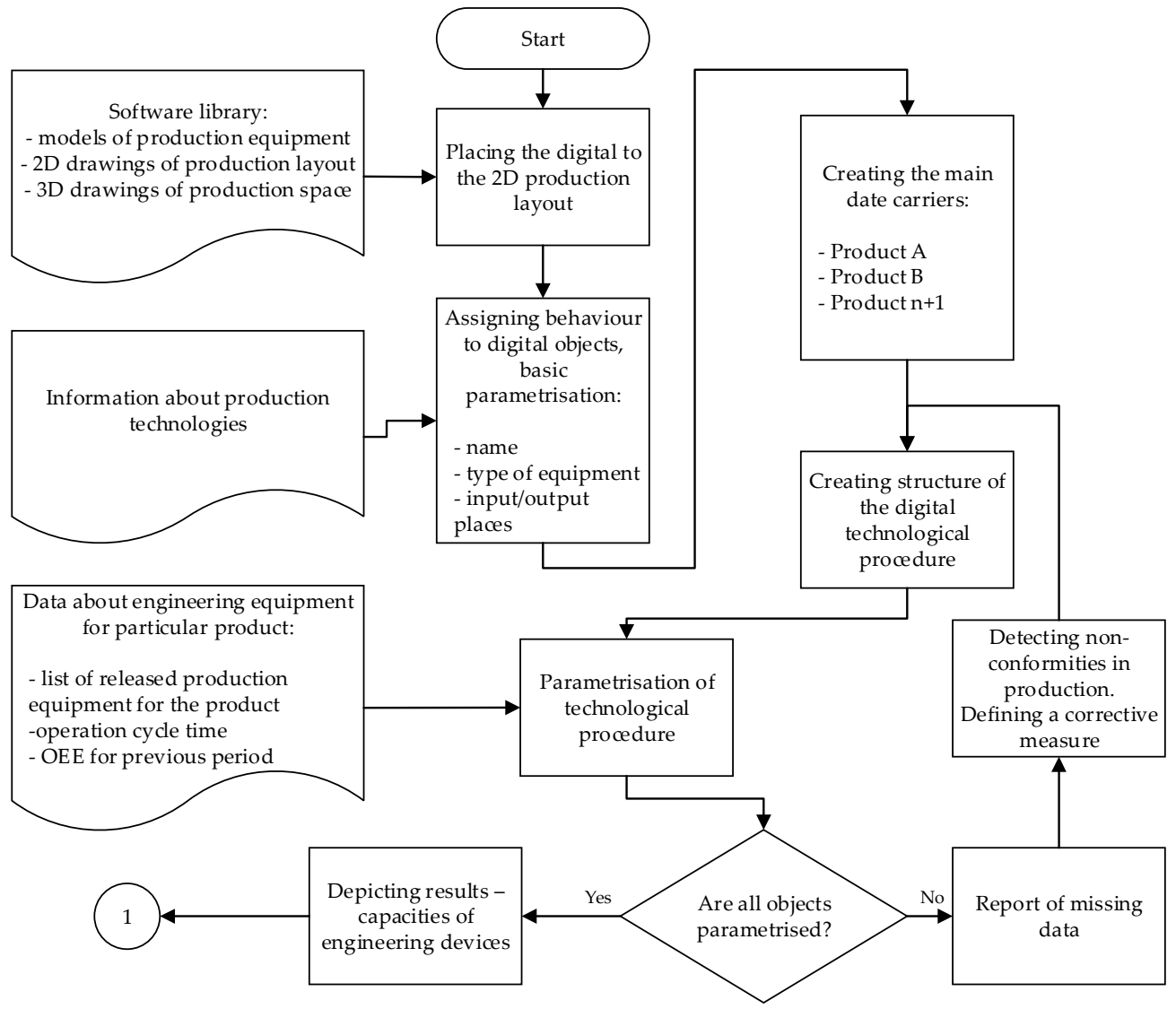

Figure 4. Stage of creating the digital production model. (source: Authors).

The primary stage represents the creation of a digital model; the user creates the digital picture of production. The products represent the main knots of the data hierarchical production model. The creation of the technological procedures and their subsequent parameterisation can depict the capacities of the engineering devices (products per shift) in regard to a particular operation (see Figure 5).

Figure 5 is by a red line marked devices Lathing that is the bottleneck of the whole system. It also can be said that the device with the highest capacity is the device second Washing. Devices Universal and first Washing is also on the higher value. Capacity on other devices fluctuating about the same value. 
Production capacity of engineering devices

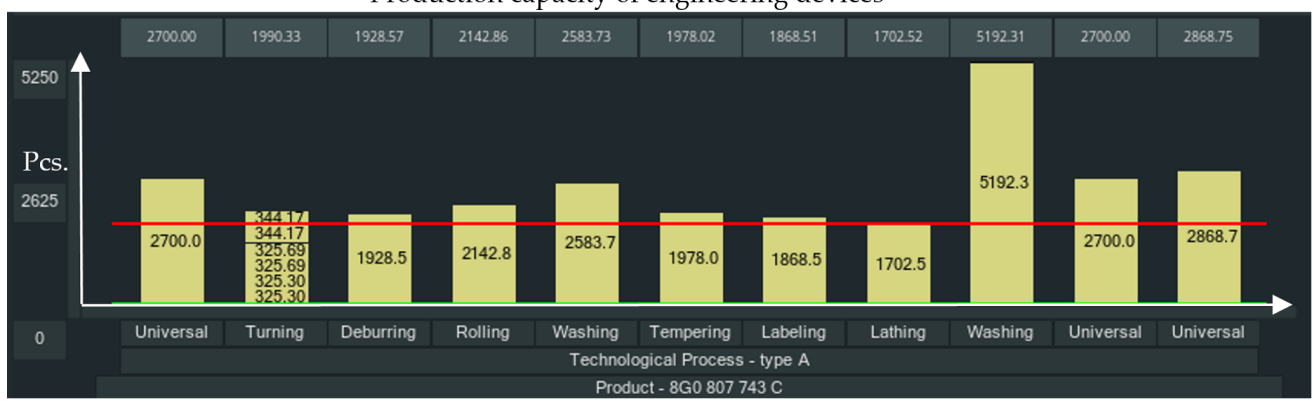

Figure 5. Resulting production capacity of engineering devices of the modelled productionan overview. (source: Authors).

\subsection{Creating Parametric Data Model of Production Process}

After creating the digital production model with the basic hierarchical arrangement, it is necessary to fulfil the individual objects and knots of the model with the data representation, i.e., to assign the time demandingness to the described activities of the production operators (see Figure 6). The data representation consists of two categories-the data unique from the point of view of the product (operation)-i.e., the measurement and set up activities and the data that are unique from the viewpoint of the activity realised by the operator on the engineering device.

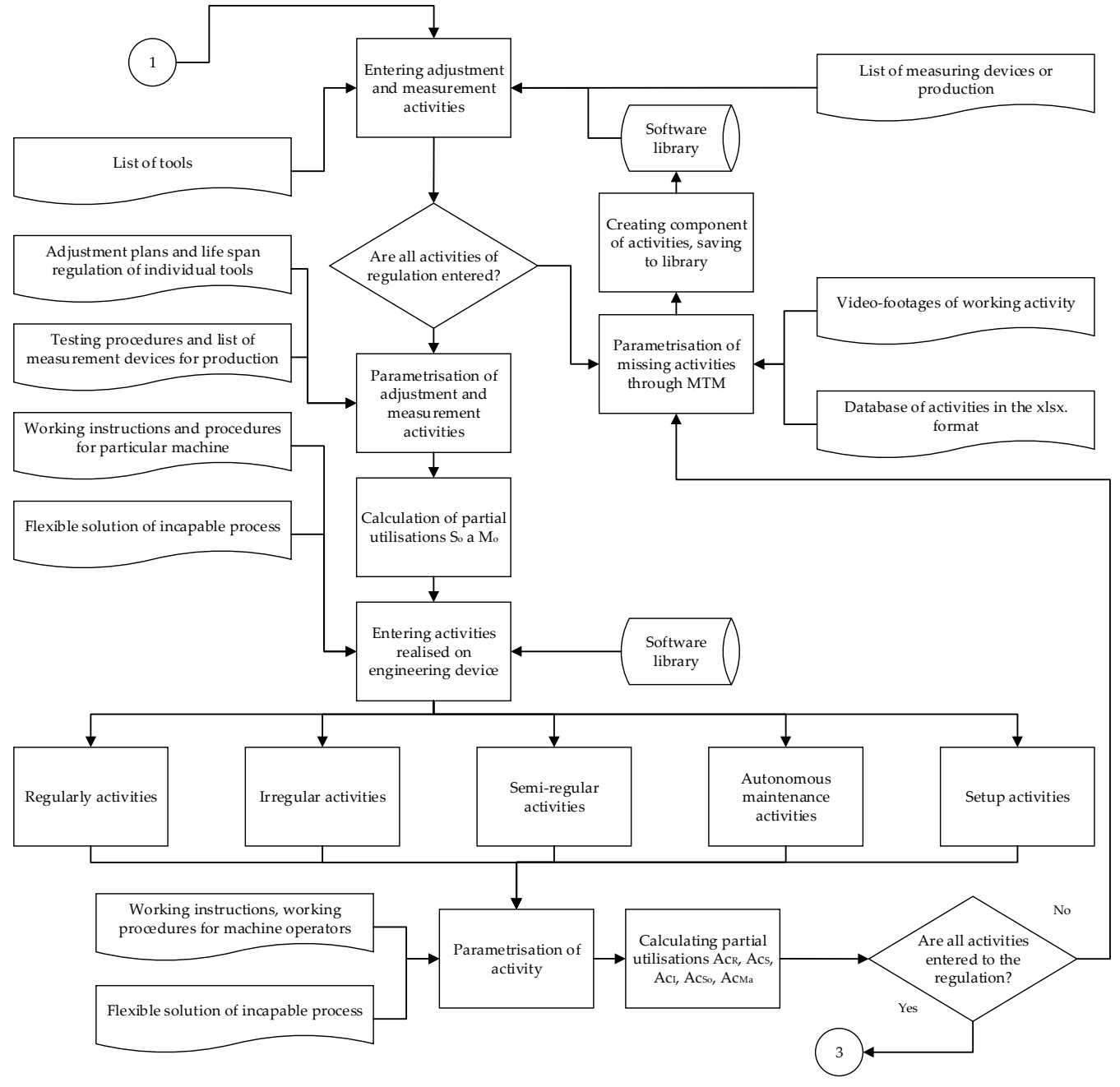

Figure 6. Stage of creating the data model design. (source: Authors). 
The data unique from the point of view of the product (operation) consists of two components - the measurement activities $\left(M_{0}\right)$ and setup activities $\left(S_{0}\right)$. The formulae for calculating individual components are as follows:

Calculation $S_{0}$ :

$$
S_{o}=\frac{\sum_{i=1}^{i=n} A_{i} * \frac{Q_{s}}{L_{t i}} * N_{t i}}{T_{A}}
$$

where $n$ is the number of the entered setup activities, $A$ is the time demandingness of the activities defined by the MTM UAS methodology, $Q_{s}$ is the required amount of production per shift (according to the shift model), $L_{t}$ is the defined life span of the tool, $N_{t}$ is the number of the tools in the machine currently machining the same surface and $T_{A}$ is the operator's available time (according to the shift model).

Calculation $M_{0}$ :

$$
M_{o}=\frac{\sum_{i=1}^{i=n} A_{i} * R_{T_{i}}}{T_{A}}
$$

where $n$ is the number of the entered setup activities, $A$ is the time demandingness of the activities defined by the MTM UAS methodology, $R_{T}$ is the repetition of the activities during the available time of the operator $\left(R_{T}=R_{f}+R_{p}+R_{t}\right)$ and $T_{A}$ is the operator's available time (according to the shift model).

After entering and parameterising all activities, we will achieve a result of the partial operator's utilisation from the point of view of exchanging the tools on his/her machines and defined measurement activities necessary for maintaining the stability of the production process through the absolute cumulative number. These partial results can be continuously depicted during operation for following up the operators' capacity development by a statistical model.

The data unique from the point of view of the activity carried out on the engineering device have to be divided into five categories. The goal of the classification into categories is to achieve a good overview of the operator's utilisation and we suggested dividing the activities into the following categories:

- The regular activities $\left(A c_{R}\right)$, the activities bound with the production volume-loading/ unloading the line, clamping the piece to the machine, to the pallet; visual inspection of how the piece is machined.

- The semi-regular activities $\left(A c_{S}\right)$. After a certain amount of the pieces checking a sample (e.g., the hardening process, etc.).

- The irregular activities $\left(A c_{I}\right)$, the activities that are not changed with the production volume. The service activities at the workplace, morning meeting with the manager.

- The SMED activities $\left(A c_{S o}\right)$, activities of setting up the machine to another product.

- The autonomous maintenance activities $\left(A c_{M a}\right)$, maintenance time per shift.

This categorisation method was chosen on the basis of a better possibility to search through a complex quantity of information when it is combined later and when variants of the employee's utilisation are created. The individual categories are defined as follows:

$$
\begin{gathered}
A c=\frac{\sum_{i=1}^{i=n} A_{i} * Q_{s_{i}}}{T_{A}} \text { for } A c_{R} \\
A c=\frac{\sum_{i=1}^{i=n} A_{i} * Q_{s_{i}} * k_{i}}{T_{A}} \text { for } A c_{S} \\
A c=\frac{\sum_{i=1}^{i=n} A_{i}}{T_{A}} \text { for } A c_{I}, A c_{S o}, A c_{M a}
\end{gathered}
$$

where $n$ is the number of the entered activities, $A$ is the time demandingness of the activities defined by the MTM UAS methodology, $Q_{s}$ is the required amount of production per shift (according to the shift model), $k$ is the coefficient of the activity's repetition, $T_{A}$ is the operator's available time (according to the shift model). 
The last stage of the methodology for creating the parametric model of the production staff's utilisation (see Figure 7) is to create the working positions. The assignment of competencies (assigning the single machine or multi-machine operation), generating the material flows from the technological procedure and the final assessment of the needs of the staff's capacities for the selected product and manufactured quantity belong also to this stage. For the need of assessing the variants generated at the working meetings of the workshop teams (various products and production plans), we suggest following the need of the overall capacity of the staff $\left(N_{o p}\right)$ through the indicator $(F z)$ given as:

$$
\begin{gathered}
N_{o p}=\sum_{i=1}^{i=n} S_{o_{i}}+M_{o_{i}}+A c_{R_{i}}+A c_{S_{i}}+A c_{I_{i}}+A c_{S o_{i}}+L o_{i}+S o_{i} \\
F z=\sum_{i=1}^{i=n} \frac{N_{o p} * T_{T}}{Q_{s}}
\end{gathered}
$$

where $n$ is the number of the created working positions, $S_{0}, M_{0}$ are the components of the measurement and setup activities of the operator, $A c_{R}, A c_{S}, A c_{I}, A c_{S o}$ are the components of the operator's activities on the assigned equipment, $L_{o}$ is the component of the logistic activities of the operator's utilisation, $S e_{o}$ is the component of the operational activities of the operator's utilisation, $N_{o p}$ is the total capacity need of the operators for the required production volume, $T_{T}$ is the operator's available time (according to the shift model), $Q_{s}$ is the required production volume per shift (according to the shift model), Fz is the total time of the human work necessary for producing one product.

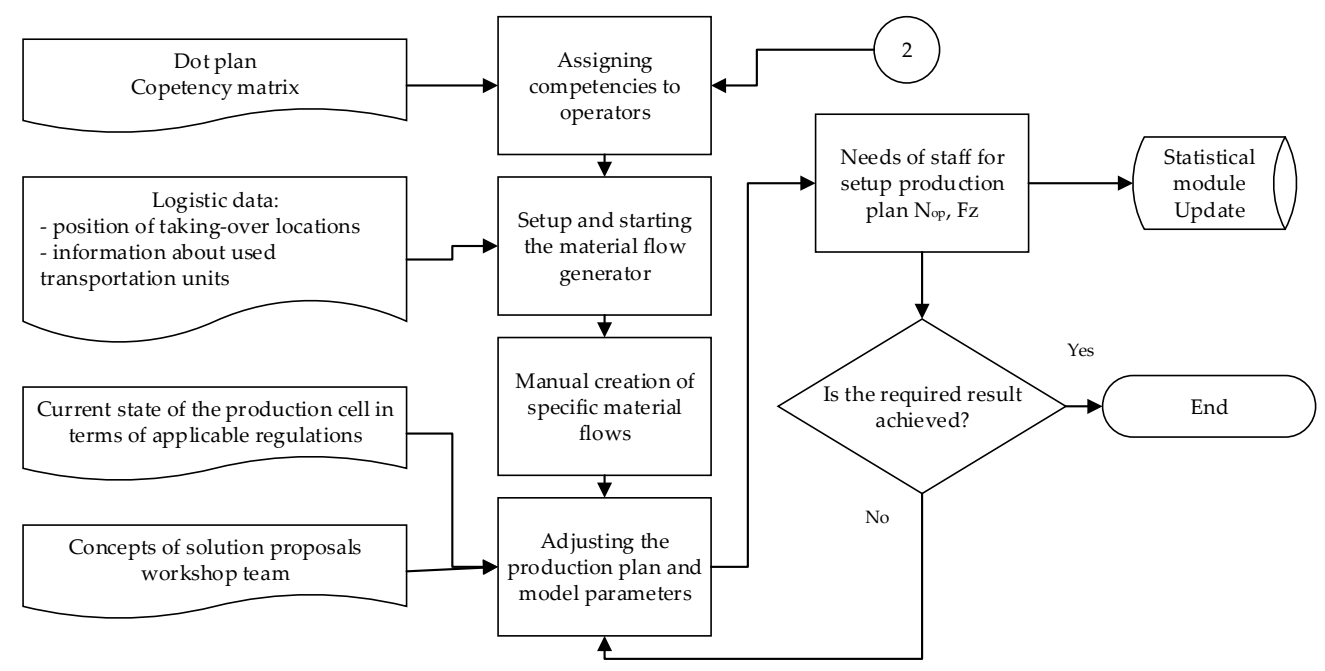

Figure 7. Stage of creating the data model design. (source: Authors).

After assessing the staff's needs of the model (the current state) of the evaluated layout we will realise changes to achieve the best solution. Through changing any input parameter or components of the digital data model's activities we update the connections in the software environment and the user gets an overview of the impacts of the entered changes. The rules and connections link the structures of the entered data and generate the output data through the defined rules out of which we can create analyses of the production workers' capacity utilisation. Based on the digital representation of the working tasks (with the defined time demandingness) it is possible to assign them to the working positions on the basis of the technological procedure or the knowledge of the managers in production. Subsequently, it is possible to quantify the volume of the necessary staff capacities for the multi-machine operation or to reveal unevenly utilised capacities.

After achieving the required results (the decision-making block) the user interface generates the following outputs: the utilisation diagrams of individual working positions, distribution of utilisation for individual categories, the value indicator $N_{o p}$ and $F z$. 


\subsection{Parametric Modelling and Assessing the Employees' Utilisation-Result}

A series of experiments in a company dealing with automotive component production was realised for the experimental verification of the designed methodology for creating the parametric production model regarding the utilisation of the production staff. The manufacturing employees' task at the production line is to machine the delivered raw material in the form of forging and cast into the form of a ready customer component serving as an output for the engine or gearbox assembly. The manufacturing operations are divided into individual sequential points according to the character of the machining operation beginning with turning and ending with heat and chemical treatment of the component being machined. The employees' task is to realise all defined activities that ensure continuous production. They are: the measurement operations according to the defined testing procedures, the exchange of the tools of the engineering machines that belong to the setup regulation on the basis of the division of the tools, the activities connected with the regular inspection of the machine parts or the cutting fluids and other tasks in the form of defined working procedures and instructions.

The designed methodology and software tool helped us create a digital model of the current state of the production stage. The calculation was realised after entering all parameters and input data. Table 1 and Figure 8 show the resulting parameters of the current state of the operators' utilisation.

Table 1. Setting up parameters and activities of the current state of the production stage-results.

\begin{tabular}{ccccccccc}
\hline & Person & $\mathbf{1}$ & $\mathbf{2}$ & $\mathbf{3}$ & $\mathbf{4}$ & $\mathbf{5}$ & $\mathbf{6}$ & $\mathbf{7}$ \\
\hline \multirow{6}{*}{ Parameter } & $S_{O}$ & 3.9 & 2.9 & 0.0 & 2.3 & 6.3 & 6.9 & 6.2 \\
& $M_{O}$ & 29.6 & 23.3 & 1.7 & 26.2 & 42.1 & 5.2 & 14.2 \\
& $A c_{R}$ & 31.2 & 0.0 & 41.6 & 100.0 & 20.8 & 27.7 & 66.7 \\
& $A c_{S}$ & 5.0 & 3.4 & 6.5 & 3.4 & 6.7 & 6.5 & 2.8 \\
& $A c_{S o}$ & 2.7 & 3.4 & 4.9 & 1.8 & 7.1 & 8.9 & 7.1 \\
& $A c_{M a}$ & 5.4 & 6.9 & 18.0 & 16.3 & 4.2 & 7.9 & 6.8 \\
& $L_{o}$ & 12.5 & 0.6 & 0.5 & 9.3 & 5.1 & 1.5 & 6.1 \\
& $S e_{o}$ & 3.7 & 3.7 & 3.7 & 3.7 & 3.7 & 3.7 & 3.7 \\
& Total & 94.0 & 46.1 & 76.9 & 162.8 & 96.1 & 68.3 & 113.5 \\
\hline
\end{tabular}

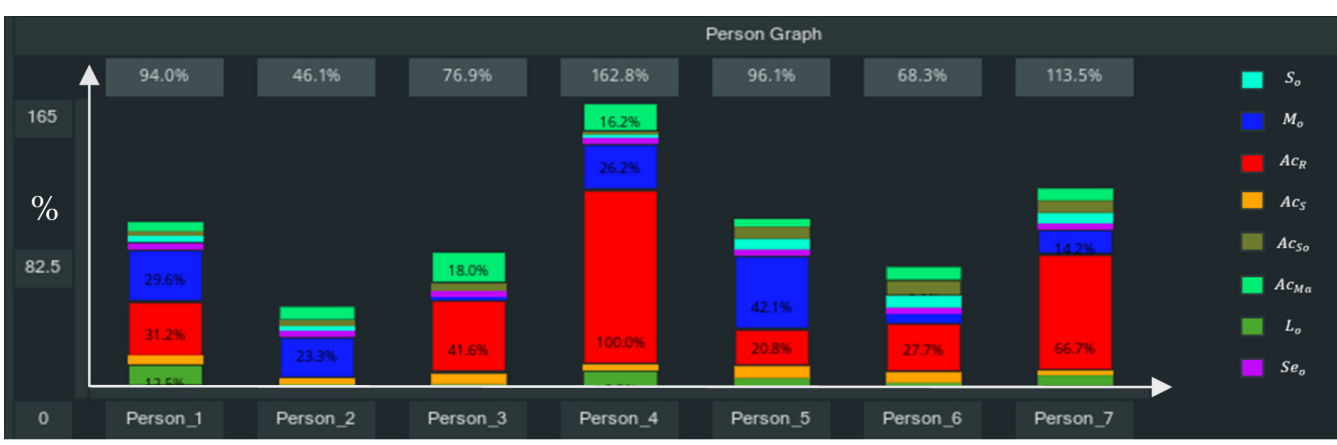

Figure 8. Current state depicted through statistical module—results. (source: Authors).

The results show that the summary of all activities defined by the regulation for the operator No. 4 and 7 is incorrect. From the mathematical point of view, the operators are significantly overloaded by up to 68.55 and $19.27 \%$. Based on verifying the realised activities through the operator's day snapshot we found out that the operator did not carry out all the defined activities according to the regulation (there is a potential for breaking the production process stability) and the production team members help him/her with other activities (a stochastic process). After studying and comparing the results we suggest a more effective distribution of the defined activity in the production stage because it is inevitable to possess correctly assigned competencies of the employees. In the case of developing qualitative shortages of the products or the process instability from the 
operator's point of view, we are able to identify the causes of their development and to take corrective measures. The data model achieves the values of the indicators $N_{o p}=6.60$ and $F z=1.47$ in the case of production $Q_{S}=3,000$.

We created several variants for adapting the layout of the defined working production activities for individual working positions/employees and subsequently, we tested these variants (see Table 2) for optimising the production stage. The following items changed in the production system:

- Variant No. 1-the distribution of the operations uniformly for individual employees according to the analysed time consumption for the given operations by the MTM UAS methodology.

- Variant No. 2-loading the workplaces, the material entering the assembly line in the reach zones up to $1 \mathrm{~m}$, a robot will automatically ensure loading the components. The inter-operational handling at individual workplaces, utilising the gravity and accumulation conveyors.

- Variant No. 3-completing two devices (production bottleneck), automated inspection activities-detecting material failures after machining by a camera system.

Table 2. Setting up parameters and activities of various variants-results.

\begin{tabular}{|c|c|c|c|c|c|c|c|c|c|}
\hline & Person & 1 & 2 & 3 & 4 & 5 & 6 & 7 & 7 \\
\hline \multirow{9}{*}{ 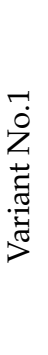 } & $S_{o}$ & 3.9 & 2.9 & 0.0 & 2.3 & 6.3 & 6.9 & 6.2 & 0 \\
\hline & $M_{o}$ & 29.6 & 23.3 & 1.7 & 26.2 & 42.1 & 5.2 & 14.2 & 0 \\
\hline & $A c_{R}$ & 31.2 & 0.0 & 41.6 & 100.0 & 20.8 & 27.7 & 66.7 & 0 \\
\hline & $A c_{S}$ & 5.0 & 3.4 & 6.5 & 3.4 & 6.7 & 6.5 & 2.8 & 0 \\
\hline & $A c_{S o}$ & 2.7 & 3.4 & 4.9 & 1.8 & 7.1 & 8.9 & 7.1 & 0 \\
\hline & $A c_{M a}$ & 5.4 & 6.9 & 18.0 & 16.3 & 4.2 & 7.9 & 6.8 & 0 \\
\hline & $L_{O}$ & 12.5 & 0.6 & 0.5 & 9.3 & 5.1 & 1.5 & 6.1 & 0 \\
\hline & $S e_{0}$ & 3.7 & 3.7 & 3.7 & 3.7 & 3.7 & 3.7 & 3.7 & 0 \\
\hline & Total & 94.0 & 46.1 & 76.9 & 162.8 & 96.1 & 68.3 & 113.5 & 0 \\
\hline \multirow{9}{*}{ 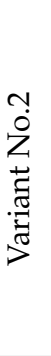 } & $S_{o}$ & 3.9 & 2.9 & 0.0 & 2.4 & 6.3 & 6.9 & 6.2 & 0.0 \\
\hline & $M_{o}$ & 29.6 & 23.3 & 1.7 & 26.2 & 43.4 & 5.2 & 14.2 & 0.0 \\
\hline & $A c_{R}$ & 41.0 & 23.0 & 41.6 & 36.0 & 20.0 & 27.7 & 46.7 & 0.0 \\
\hline & $A c_{S}$ & 5.0 & 3.3 & 6.5 & 3.3 & 6.7 & 6.5 & 2.8 & 0.0 \\
\hline & $A c_{S o}$ & 2.7 & 3.4 & 4.9 & 1.8 & 7.1 & 8.9 & 7.1 & 0.0 \\
\hline & $A c_{M a}$ & 5.4 & 7.9 & 18.0 & 16.2 & 3.0 & 7.9 & 6.8 & 0.0 \\
\hline & $L_{0}$ & 3.1 & 1.6 & 0.5 & 9.3 & 2.2 & 1.5 & 6.1 & 0.0 \\
\hline & $S e_{0}$ & 3.7 & 32.9 & 3.7 & 3.7 & 3.7 & 3.7 & 3.7 & 0.0 \\
\hline & Total & 94.4 & 98.2 & 76.9 & 98.9 & 92.4 & 68.3 & 93.5 & 0.0 \\
\hline \multirow{9}{*}{ 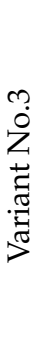 } & $S_{o}$ & 3.9 & 2.8 & 0.0 & 2.4 & 7.0 & 10.0 & 0.3 & 8.8 \\
\hline & $M_{o}$ & 29.6 & 23.3 & 1.7 & 26.2 & 54.9 & 31.0 & 1.6 & 16.0 \\
\hline & $A c_{R}$ & 41.0 & 23.0 & 41.6 & 36.0 & 11.0 & 44.0 & 40.7 & 45.0 \\
\hline & $A c_{S}$ & 5.0 & 3.4 & 6.5 & 3.4 & 6.7 & 0.0 & 6.5 & 2.8 \\
\hline & $A c_{S o}$ & 2.7 & 3.4 & 4.9 & 1.8 & 7.1 & 3.6 & 8.9 & 7.1 \\
\hline & $A c_{M a}$ & 5.4 & 7.9 & 18.0 & 16.3 & 3.0 & 4.7 & 6.2 & 6.8 \\
\hline & $L_{o}$ & 3.1 & 1.6 & 0.5 & 9.3 & 2.2 & 1.5 & 0.9 & 6.1 \\
\hline & $S e_{0}$ & 3.7 & 32.9 & 3.7 & 3.7 & 3.7 & 3.7 & 3.7 & 3.7 \\
\hline & Total & 94.4 & 98.3 & 76.9 & 99.1 & 95.6 & 98.5 & 68.8 & 96.3 \\
\hline
\end{tabular}

After making any change the system interactively assessed the impact and calculated the resulting parameters of the necessary staff capacities of the designed production system. Table 3 and Figure 9 bring the resulting design parameters. 
Table 3. Setting up parameters, activities of the proposed state of the production stage-results.

\begin{tabular}{ccccccccc}
\hline & Person & $\mathbf{1}$ & $\mathbf{2}$ & $\mathbf{3}$ & $\mathbf{4}$ & $\mathbf{5}$ & $\mathbf{6}$ & $\mathbf{7}$ \\
\hline \multirow{6}{*}{ Parameter } & $S_{O}$ & 3.9 & 2.8 & 0.0 & 2.4 & 7.0 & 10.0 & 0.3 \\
& $M_{O}$ & 29.6 & 23.3 & 1.7 & 26.2 & 54.9 & 31.0 & 1.6 \\
& $A c_{R}$ & 41.0 & 23.0 & 41.6 & 36.0 & 11.0 & 44.0 & 40.7 \\
& $A c_{S}$ & 5.0 & 3.4 & 6.5 & 3.4 & 6.7 & 0.0 & 6.5 \\
& $A c_{S o}$ & 2.7 & 3.4 & 4.9 & 1.8 & 7.1 & 3.6 & 8.9 \\
& $A c_{M a}$ & 5.4 & 7.9 & 18.0 & 16.3 & 3.0 & 4.7 & 6.2 \\
& $L_{O}$ & 3.1 & 1.6 & 0.5 & 9.3 & 2.2 & 1.5 & 0.9 \\
& $S e_{o}$ & 3.7 & 32.9 & 3.7 & 3.7 & 3.7 & 3.7 & 3.7 \\
& Total & 94.4 & 98.2 & 76.9 & 98.9 & 95.7 & 98.4 & 68.9 \\
\hline
\end{tabular}

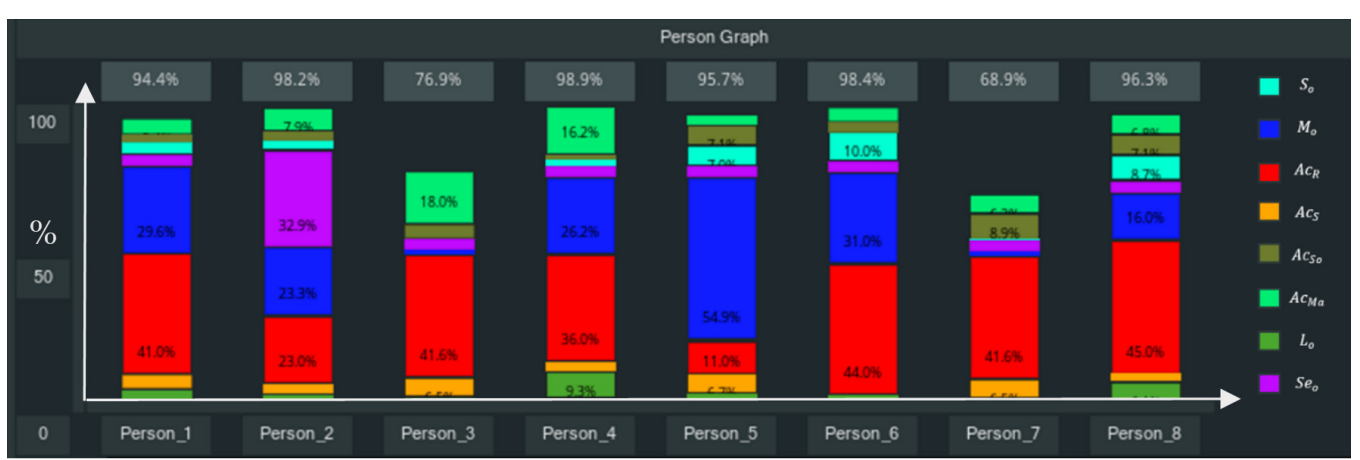

Figure 9. Designed state depicted through the statistic module-results. (source: Authors).

After the result analysis, we can say that we succeeded in adapting the division of activities of all operators in such a way that the data model does not create any operator's overload. The data model achieves for $Q_{S}=3,600$ the indicator values of $N_{o p}=7.31$ and $F z=1.36$. The designed changes brought a $20 \%$ increase in manufacturing in the production stage with one more operator. The $F z=1.36$ coefficient value is lower and it means that after implementing the deigned changes in production it will be necessary to use a $7.61 \%$ lower amount of the human work compared with the current state.

We can claim that our software enriched with the designed methodology can mediate information and feedback about the impact of the designed changes in the production layout for the capacity need of the production staff. The case study proved it was possible to reveal a remarkable potential for designing the existing manufacturing systems through this software solution. The practical benefits of this solution include especially the shortening of the necessary time for designing the production layout and its subsequent planning especially in the phase of the variant design. The possibility of verifying a more extensive quantity of solutions when we take into account various limiting conditions is closely connected with this fact. As this designed solution reduces the time necessary in the phase of the variant design, the costs inevitable for creating a new production organisation or expenses for changes in the existing production layout are also decreased.

\section{Discussion}

The following questions arose when solving the usage of the parametric modelling and utilisation assessment of the production staff as a basic material for the production aggregate planning:

- What are the main advantages of designing production using the parametric data model for production staff utilisation?

- The process of designing the production layout is often of a complicated character. At the same time, there is a requirement to achieve the solution in the shortest possible time. It is necessary to take into account several factors and this fact often makes it impossible to find an optimal solution and it is necessary to satisfy with the available solution. The advantage is that if we want to change something or to improve a certain 
process in the company, we can try various solutions by creating variants. We are able to analyse what impact the change of the production layout brings (adding or updating a machine) not only concerning the amount/volume of production but also regarding the capacity need of the staff. Thanks to interconnecting the project system environment and the data model, it is possible to test all possible setup combinations and limitations without any need to change physically the layout in the production space. The interactive character of the design system will also ensure calculating the observed indicators and offers the user to assess the designed changes in real-time. In practice, we will significantly reduce the costs for creating the production layout in the phase of the variant design.

- Are there any shortages for using this methodology?

- Of course, the usage of this method for designing the production layout also brings shortages, e.g., the form of saving the data of industrial organisations. The companies save the majority of the data in the electronic form (approximately 60\%); however, the problem is that the data do not create structural units that could be imported and utilised for the capacity dimensioning and assessment of the production staff utilisation immediately. The other data are collected and assessed in one-day intervals and saved in the hard-copy form, and they are utilised according to the need for identifying the production problems. They are saved in the company archives and their usage is very laborious and frequently time demanding. Thanks to the two, we created several data models of the production stages with the layouts of the defined manufacturing activities for individual working positions/employees. Based on analysing various types of manufacturing regulations, we will gradually develop a module of the general importer that will make the process of entering a large amount of data from various designed production forms of the industrial organisations more effective.

- Were there any discrepancies between the assessment of the data model by the designed methodology and the current state in production?

- There were discrepancies between the software assessment and the opinion (the professional estimation on the basis of experience) of an employee responsible for planning the manufacturing capacities. However, after presenting all input data, we found cases there were activities in production that were not defined by the valid documentation or were ambiguously quantified from the point of view of the number/duration. The subsequent analyses of the capacity utilisation of the employees by the activities defined by the valid regulations and activities without any valid regulation proved there was a $5-15 \%$ increase in the total capacity of the staff. From the process point of view, these activities were inevitable for maintaining the quality of the final product defined by the customer; however, they were missing not only in the valid documentation of the company regulations but also in calculations of the costs for production. During the manufacturing process, the company generatedin this way - a constant loss of the production staff because the real production costs were higher than the planned ones. In this case, the potential of the designed methodology was transparent in supporting the aggregate planning and calculating the costs.

- What is the further direction of the research in this area?

- We would like to continue this research area and enrich the module supporting the planning procedure by further functions and calculations. We gathered a basis of data and we want to continue evaluating the parameters of the production system from the mathematical point of view, e.g., Process Lead Time (PLT) for detecting the inventories, Value-added Activities (VA) and the Process Cycle Efficiency (according to the Little's Principle) for the overall assessment of the designed system's effectiveness. The creation of the algorithms for defining the optimal WIP and connecting the module supporting the production capacity planning on IoT will be a very important part of our research. The created interconnection will enable utilising the data from the 
shift card or the engineering devices. Based on the saved data of a particular shift card and the engineering device the system will calculate the real OEE. This function will help us acquire more accurate data necessary for creating a production plan and calculating the capacity of the engineering devices.

- What is the usability of the methodology in practice?

- The methodology described in the article requires its application to meet several prerequisites. Strictly defined position-Working positions that will be designed must be defined from the point of view of workplaces. Strictly defined working activitiesto balance the workload and utilisation, it is necessary to have defined activities their range and duration. Strictly defined limiting conditions-for the correct design of the production process and its workload, knowledge of the spatial limitations (for example, wall size, dimensions of the hall) and time constraints (for example, calendar, worker time fonds, shift duration) is required. For the above reasons, the methodology is designed for discrete production with sufficient seriality and repeatability. The proposed model gives engineers in practice a powerful tool for variant modelling and simulation of production processes in order to optimally utilisation human capacities.

\section{Conclusions}

This article described the design of integrating the most suitable methodology of parametric modelling and dimensioning the production staff with interactive software environment for designing 3D production layouts. The published case study shows how useful the advanced technologies in the area of designing and planning the production layout in the phase of the concept designs taking into account various limiting conditions can be. The functionality of the designed solution was verified in the industry on the basis of the real production data. Results from the case study indicate that the designed changes brought a $20 \%$ increase in manufacturing in the production stage with one more operator. The $\mathrm{Fz}=1.36$ coefficient value is lower, and it means that after implementing the design changes in production, it will be necessary to use a $7.61 \%$ lower amount of human work compared with the current state. Based on the results, it is possible to say that the designed system of the parametric modelling and assessment of the production staff utilisation fulfils all requirements. It offers an optimal solution to the defined problem, and it takes into account the limiting conditions and serves as a basis for aggregate production planning. The design tool enriched with the mutually interconnected modules and communicating elements can mediate information and feedback in the process of creating changes for the further decision-making of the industrial organisations. The long-term sustainability of the manufacturing industrial organisations can be viewed through the tools that could help maintain their existence and prosperity. Thanks to the innovative technologies (e.g., the simulation technologies, interactive design systems supported by the function of the parametric modelling of production), companies can design and verify the accuracy of the new product solutions before the process begins in the production space in a simple and effective way.

Author Contributions: All authors contributed equally to the research presented in this paper and to the preparation of the final manuscript. All authors have read and agreed to the published version of the manuscript.

Funding: This article was created with support of VEGA project: VEGA 1/0225/21.

Institutional Review Board Statement: Not applicable.

Informed Consent Statement: Not applicable.

Data Availability Statement: The data presented in this study are available on request from the corresponding author. The full text of data is not publicly available due to company privacy.

Acknowledgments: The authors want to acknowledge the support of CEIT (Central European Institute of Technology) in Žilina. 
Conflicts of Interest: The authors declare no conflict of interest.

\section{References}

1. Krolczyk, J.B.; Krolczyk, G.M.; Legutko, S.; Napiorkowski, J.; Hloch, S.; Foltys, J.; Tama, E. Material flow optimization-A case study in automotive industry. Tech. Vjesn. 2015, 22, 1447-1456. [CrossRef]

2. Stanisavljevic, N.; Brunner, P.H. Combination of material flow analysis and substance flow analysis: A powerful approach for decision support in waste management. Waste Manag. Res. 2014, 32, 733-744. [CrossRef] [PubMed]

3. Wiecek, D.; Wiecek, D.; Dulina, L. Materials Requirement Planning with the Use of Activity Based Costing. Manag. Syst. Prod. Eng. 2020, 28, 3-8. [CrossRef]

4. Fusko, M.; Rakyta, M.; Dulina, L.; Sulirova, I.; Edl, M. Digitization in the Technical Service Management System. MM Sci. J. 2018, 2018, 2260-2266. [CrossRef]

5. Sevigne-Itoiz, E.; Gasol, C.M.; Rieradevall, J.; Gabarrell, X. Methodology of supporting decision-making of waste management with material flow analysis (MFA) and consequential life cycle assessment (CLCA): Case study of waste paper recycling. J. Clean. Prod. 2014, 105, 253-262. [CrossRef]

6. Mutha, N.H.; Patel, M.; Premnath, V. Plastics materials flow analysis for India. Resour. Conserv. Recycl. 2006, 47, $222-244$. [CrossRef]

7. Kovács, G.; Kot, S. Facility layout redesign for efficiency improvement and cost reduction. J. Appl. Math. Comput. Mech. 2017, 16, 63-74. [CrossRef]

8. Sobaszek, L.; Gola, A.; Kozlowski, E. Application of Survival Function in Robust Scheduling of Production Jobs. In Proceedings of the 2017 Federated Conference on Computer Science and Information Systems (fedcsis), Prague, Czech Republic, 3-6 September 2017; Ganzha, M., Maciaszek, L., Paprzycki, M., Eds.; IEEE: New York, NY, USA, 2017; pp. 575-578. [CrossRef]

9. Kliment, M.; Pekarcikova, M.; Trebuna, P.; Trebuna, M. Application of TestBed 4.0 Technology within the Implementation of Industry 4.0 in Teaching Methods of Industrial Engineering as Well as Industrial Practice. Sustainability 2021, 13, 8963. [CrossRef]

10. Haluska, M.; Gregor, M. Concept of the system for design and optimisation of configurations in new generation of manufacturing systems. Int. J. Manag. Soc. Sci. Res. Rev. 2016, 1, 181-184.

11. Hnilica, R.; Jankovsky, M.; Dado, M.; Messingerova, V. Experimental Evaluation of Combined Effects of Risk Factors in Work Environment. In Proceedings of the 12th International Scientific Conference Engineering for Rural Development, Jelgava, Latvia, 23-24 May 2013; Osadcuks, V., Ed.; Latvia Univ Agriculture, Faculty Engineering, Inst Mechanics: Jelgava, Latvia, 2013; pp. 577-583.

12. Kuzma, D.; Korba, P.; Hovanec, M.; Dulina, L. The Use of CAX Systems as a Tool for Modeling Construction Element in the Aviation Industry. Nase More 2016, 63, 134-139. [CrossRef]

13. Bubeník, P.; Horák, F. Proactive approach to manufacturing planning. Qual. Innov. Prosper. 2014, 18, 23-32. [CrossRef]

14. Pekarcikova, M.; Trebuna, P.; Klimenti, M.; Kral, S.; Dic, M. Modelling and Simulation the Value Stream Mapping-Case Study. Manag. Prod. Eng. Rev. 2021, 12, 107-114. [CrossRef]

15. Pekarcikova, M.; Trebuna, P.; Kliment, M.; Dic, M. Solution of Bottlenecks in the Logistics Flow by Applying the Kanban Module in the Tecnomatix Plant Simulation Software. Sustainability 2021, 13, 7989. [CrossRef]

16. Sammen, S.S.; Ghorbani, M.A.; Malik, A.; Tikhamarine, Y.; AmirRahmani, M.; Al-Ansari, N.; Chau, K.-W. Enhanced Artificial Neural Network with Harris Hawks Optimization for Predicting Scour Depth Downstream of Ski-Jump Spillway. Appl. Sci. 2020, 10, 5160. [CrossRef]

17. Krajčovič, M. Modern approaches of manufacturing and logistics systems design. In Digitálny Podnik [Electronic Source]; CEIT SK: Žilina, Slovakia, 2011; p. 12, ISBN 978-80-970440-1-5.

18. Jamalnia, A.; Yang, G.-B.; Feili, A.; Xu, D.-L.; Jamail, G. Aggregate production planning under uncertainty: A comprehensive literature survey and future research directions. Int. J. Adv. Manuf. Technol. 2019, 102, 159-181. [CrossRef]

19. Vogel, T.; Almada-Lobo, B.; Almeder, C. Integrated versus hierarchical approach to aggregate production planning and master production scheduling. OR Spectr. 2017, 39, 193-229. [CrossRef]

20. Hafezalkotob, A.; Chaharbaghi, S.; Lakeh, T.M. Cooperative aggregate production planning: A game theory approach. J. Ind. Eng. Int. 2019, 15, 19-37. [CrossRef]

21. Antonio Campo, E.; Jose Alejandro, C.C.; Rodrigo Andrés, G.M. Linear Programming for Aggregate Production Planning in a Textile Company. Fibres Text. East. Eur. 2018, 26, 13-19. [CrossRef]

22. De Lessio, M.P.; Wynn, D.C.; Clarkson, P.J. Modelling the planning system in design and development. Res. Eng. Des. 2019, 30, 227-249. [CrossRef]

23. Metaxiotis, K.; Askounis, D.; Psarras, J. An Object-Oriented Analysis and Design of a Model for Production Planning and Control in Industry. Int. J. Adv. Manuf. Technol. 2001, 18, 657-664. [CrossRef]

24. Reza, K. A genetic algorithm to integrate a comprehensive dynamic cellular manufacturing system with aggregate planning decisions. Int. J. Manag. Sci. Eng. Manag. 2020, 15, 138-154. [CrossRef]

25. Gerd, J.H.; Brandenburg, M. A sustainable aggregate production planning model for the chemical process industry. Comput. Oper. Res. 2018, 94, 154-168. [CrossRef]

26. Campbell, G.M. Cross-Utilization of Workers Whose Capabilities Differ. Manag. Sci. 1999, 45, 722-732. [CrossRef] 
27. Grznár, P.; Gregor, M.; Mozol, Š.; Schickerle, M.; Vavrík, V.; Mozolová, L. Optimization of Logistics Process in Context of Smart Logistics by Using Computer Simulation-Case Study. Proc. CBU Econ. Bus. 2020, 1, 84-90. [CrossRef]

28. Grznár, P.; Krajčovič, M.; Gola, A.; Dulina, L’; Furmannová, B.; Mozol, Š.; Plinta, D.; Burganová, N.; Danilczuk, W.; Svitek, R. The Use of a Genetic Algorithm for Sorting Warehouse Optimisation. Processes 2021, 9, 1197. [CrossRef]

29. Han, C.H.; Park, J.Y.; Kam, S.; Kim, S.A.; Park, K.S. A Model Study on Medical Utilization of Workers with Non-Occupational Diseases: An Application of the Theory of Planned Behavior. Korean J. Occup. Environ. Med. 2006, 18, 284. [CrossRef]

30. Pan, L.; Kleiner., B.H. Aggregate planning today. Work. Study 1995, 44, 4-7. [CrossRef]

31. Osvaldova, L.M.; Petho, M. Occupational Safety and Health During Rescue Activities. In Proceedings of the 6th International Conference on Applied Human Factors and Ergonomics (ahfe 2015) and the Affiliated Conferences, Ahfe 2015, Las Vegas, NV, USA, 26-30 July 2015; Ahram, T., Karwowski, W., Schmorrow, D., Eds.; Elsevier Science Bv: Amsterdam, The Netherlands, 2015; Volume 3, pp. 4287-4293. [CrossRef]

32. Malakooti, B. Operations and Production Systems with Multiple Objectives; Wiley: Hoboken, NJ, USA, 2014; p. 1114, ISBN 978-0470-03732-4.

33. Gale. The Encyclopedia of Management, 6th ed.; Gale Group: Farmington Hills, MI, USA, 2009; p. 1094s, ISBN 978-1-4144-3803-0.

34. Bowman, E.H. Production Scheduling by the Transportation Method of Linear Programming. Oper. Res. 1956, 4, 100-103. [CrossRef]

35. Dejonckheere, J.; Disney, S.M.; Lambrecht, M.; Towill, D.R. The dynamics of aggregate planning. Prod. Plan. Control. 2003, 14, 497-516. [CrossRef]

36. Gregor, M.; Gregor, T.; Magvaši, V. Internet vecí (IoT). ProIN—Product. Innov. 2015, 16, 35-41.

37. Gregor, T.; Gregor, M.; Macúš, P.; Michulek, T. CEIT Smart Factory. ProIN—Product. Innov. 2017, 18, 14-18.

38. Bécue, A.; Maia, E.; Feeken, L.; Borchers, P.; Praça, I. A New Concept of Digital Twin Supporting Optimisation and Resilience of Factories of the Future. Appl. Sci. 2020, 10, 4482. [CrossRef]

39. Buckova, M.; Skokan, R.; Fusko, M.; Hodon, R. Designing of logistics systems with using of computer simulation and emulation. In Proceedings of the 13th International Scientific Conference on Sustainable, Modern and Safe Transport (TRANSCOM 2019), Horny Smokovec, Slovakia, 29-31 May 2019; Transportation Research Procedia. Volume 40, pp. 978-985.

40. Vavrík, V.; Gregor, M.; Grznár, P.; Mozol, Š.; Schickerle, M.; Ďurica, L.; Marschall, M.; Bielik, T. Design of Manufacturing Lines Using the Reconfigurability Principle. Mathematics 2020, 8, 1227. [CrossRef]

41. Furmann, R.; Macuš, P.; Štefánik, A.; Herčko, J. Interactive system for design of Factories of the Future. In Proceedings of the CLC 2018-Carpathian Logistics Congress, Prague, Czech Republic, 3-5 December 2018; pp. 116-122, ISBN 978-80-87294-88-8. 